\title{
Performance Limits of Photoelectrochemical CO2 Reduction Based on Known Electrocatalysts and the Case for Two-Electron Reduction Products
}

\author{
Vesborg, Peter Christian Kjærgaard; Seger, Brian
}

Published in:

Chemistry of Materials

Link to article, DOI:

10.1021/acs.chemmater.6b03927

Publication date:

2016

Document Version

Peer reviewed version

Link back to DTU Orbit

Citation (APA):

Vesborg, P. C. K., \& Seger, B. (2016). Performance Limits of Photoelectrochemical CO Reduction Based on Known Electrocatalysts and the Case for Two-Electron Reduction Products. Chemistry Of Materials, 28(24), 8844-8850. https://doi.org/10.1021/acs.chemmater.6b03927

\section{General rights}

Copyright and moral rights for the publications made accessible in the public portal are retained by the authors and/or other copyright owners and it is a condition of accessing publications that users recognise and abide by the legal requirements associated with these rights.

- Users may download and print one copy of any publication from the public portal for the purpose of private study or research.

- You may not further distribute the material or use it for any profit-making activity or commercial gain

- You may freely distribute the URL identifying the publication in the public portal 


\title{
Performance limits of photoelectrochemical $\mathrm{CO}_{2}$
}

\section{reduction based on known electrocatalysts and}

\section{the case for 2-electron reduction products}

\author{
Peter C. K. Vesborg ${ }^{A, *}$, Brian Seger ${ }^{A}$ \\ *Corresponding author peter.vesborg@fysik.dtu.dk \\ A SurfCat, Dept. of Physics, Technical University of Denmark (DTU) \\ B. 312, Fysikvej, DK-2800, Denmark
}

\begin{abstract}
Solar-driven reduction of $\mathrm{CO}_{2}$ to solar fuels as an alternative to $\mathrm{H}_{2}$ via water splitting is an intriguing proposition. We model the Solar-To-Fuel (STF) efficiencies using realistic parameters based on recently reported $\mathrm{CO}_{2}$ reduction catalysts with a high performance tandem photoabsorber structure. CO and formate, which are both 2-electron reduction products, offer surprisingly competitive STF efficiencies (20.0\% and 18.8\%) very close to solar $\mathrm{H}_{2}(21.8 \%)$ despite markedly worse reduction catalysis. The slightly lower efficiency towards carbon products is mainly due to electrolyte resistance - not overpotential. Surprisingly, using a cell design where electrolyte resistance is minimized makes formate the preferred product from an efficiency standpoint (reaching 22.7\% STF efficiency). On the other hand, going beyond 2electron reductions the more highly reduced products seem unviable with presently available electrocatalysts due to excessive overpotentials and poor selectivity. Breaking up the multi-
\end{abstract}


electron reduction pathway into individually optimized, separate 2-electron steps could be a way forward. 


\section{TOC GRAPHICS}

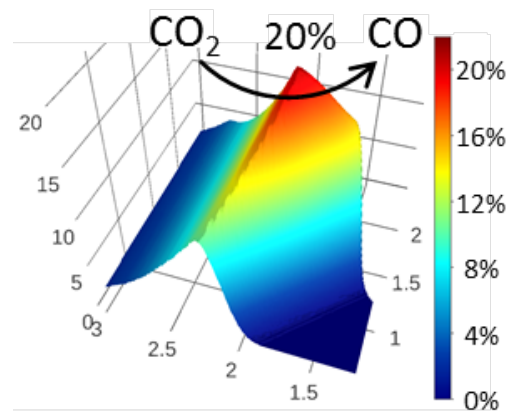

The research efforts towards solar fuel synthesis technologies have mostly focused on splitting water into hydrogen (fuel) and an oxygen bi-product. The reasons for this are several: Hydrogen is perhaps the simplest molecule to produce, it has a reasonable free energy content and there exists excellent hydrogen evolution electrocatalysts. ${ }^{1,2}$ It is well known that the optimal configuration for direct photoelectrochemical $\left(\mathrm{PEC}^{3}\right)$ solar driven water splitting is a two-photon (or “tandem”)-configuration. In a tandem device, two photoabsorbers - each providing photovoltage under illumination, are stacked and series connected such that their combined photovoltage can overcome the thermodynamics of water splitting in addition to all the losses associated with electrochemical overpotentials and resistive losses in the electrolyte and membrane. Both photoabsorbing cells should be designed to evenly split the available solar photons in order to achieve the highest possible photocurrent density while maintaining sufficiently high photovoltage to run the reaction. ${ }^{4}$

\section{Photoelectrochemical water splitting}

The specific case of water splitting is covered in both older ${ }^{5,6}$ and more recent literature. ${ }^{7-10}$ Depending on the exact assumptions related to losses, the optimum band gaps for the top- and bottom cells in the tandem are in the range of $1.7 \mathrm{eV}-1.9 \mathrm{eV}$ and $0.95 \mathrm{eV}-1.4 \mathrm{eV}$ respectively; 
and the corresponding maximum achievable solar-to-hydrogen (STH) efficiency ${ }^{11}$ is in the range of $20 \%-29 \%$.

In order to guide the research despite the large gamut of parameters and no obvious "right" set of parameter choices two web-based modelling (WBM) tools have been launched: $\underline{\text { SPECDO }}$ and Solarfuelsmodeling. SPECDO.epfl.ch, by the Haussener group at EPFL, provides a holistic, systems modeling approach including economics ${ }^{12}$ while Solarfuelsmodeling.com, focusses on the core photoabsorber stack and simulates PEC device thermodynamic performance - not just for water splitting, but for any energy harvesting reaction. ${ }^{13}$ The WBM software takes a thermodynamic approach based on the diode equation to calculate the IV-behavior of the core photoabsorber stack. This works well for “buried junction” PEC, but it may also be applicable for semiconductor-liquid junction devices, provided a good band alignment between the semiconductor and electrolyte. The analysis presented here was performed using this freely available WBM tool.

Besides the optical aspects of the device and the important compromise of the solar absorber bandgaps, a significant amount of analysis of the engineering and plant design aspects of the cell has appeared in the PEC solar water splitting literature. ${ }^{14-17}$ 


\begin{tabular}{|l|r|l|}
\hline \multicolumn{3}{|c|}{ Photoabsorber parameters } \\
\hline Temperature & 298 & $\mathrm{~K}$ \\
\hline Optical water thickness & 2 & $\mathrm{~cm}$ \\
\hline Parasitic light loss & 10 & $\%$ \\
\hline $\begin{array}{l}\text { Dark saturation current } \\
\text { (multiple of theoretical } \\
\text { minimum) }\end{array}$ & 100 & - \\
\hline Shunt resistance & 10000 & $\Omega / \mathrm{cm}^{2}$ \\
\hline Series resistance & 1 & $\Omega \mathrm{cm}^{2}$ \\
\hline
\end{tabular}

\begin{tabular}{|l|r|l|}
\hline \multicolumn{3}{|c|}{ Electrochemical parameters } \\
\hline Faradaic efficiency & 100 & $\%$ \\
\hline $\begin{array}{l}\text { OER onset overpotential } \\
\left(1 \mathrm{~mA} / \mathrm{cm}^{2}\right)\end{array}$ & 320 & $\mathrm{mV}$ \\
\hline OER Tafel slope & 40 & $\mathrm{mV} /$ decade \\
\hline Ionic path length & 0.5 & $\mathrm{~cm}$ \\
\hline
\end{tabular}

\section{Table 1 Standard parameters in common for all simulations presented in this work.}

\section{Photoelectrochemical $\mathrm{CO}_{2}$ reduction}

Compared to the analysis carried out for PEC-driven hydrogen production, comparatively little analysis has so far appeared in the literature on other PEC-driven reactions, although a lively debate pro et contra water splitting vs. $\mathrm{CO}_{2}$ reduction is currently ongoing. ${ }^{18-20}$ This is in spite of the fact that a substantial research effort currently devoted to finding electrocatalysts capable of directly reducing $\mathrm{CO}_{2}$ into energetic compounds such as methane, ethane, and ethanol and, in turn, to integrate such $\mathrm{CO}_{2}$ reduction catalysts into PEC solar harvesting systems. ${ }^{21-24}$ Only in late 2015 did the first analysis of PEC-driven $\mathrm{CO}_{2}$ reduction appear. ${ }^{25}$ In this paper Singh et al . modeled single, double and triple junction devices driving various fuel synthesis reactions running at the thermoneutral potential (i.e. a hypothetical case). They find that the highest solar harvesting efficiency occurs for $\mathrm{CO}_{2}$ reduction to $\mathrm{CO}$, and the best configuration is a double junction (tandem) device. It must be emphasized, however, that a simple thermoneutral potential analysis ignores catalytic and ohmic losses, which are unavoidable in any realistic device. Hence Singh et al. report a theoretical solar-to-hydrogen (STH) efficiency of 35.4\% for a tandem device which, as noted above, is at least $7 \%$ abs higher than a careful "best case” analysis ${ }^{7}$ and roughly $15 \%$ abs higher than a very careful "realistic case” analysis. ${ }^{13}$ On the other hand, Singh et al. also modeled double- and triple junction devices using experimental $\mathrm{CO}_{2}$-reduction current-voltage 
data and found that using a copper-based $\mathrm{CO}_{2}$-reduction catalyst and an $\mathrm{IrO}_{2}$-based oxygen evolution catalyst it should be possible to directly convert $\mathrm{CO}_{2}$ and water into a $\mathrm{H}_{2} / \mathrm{CH}_{4}$ mixture with around 20.3\% solar-to-fuel (STF) efficiency. However, it is worth noting, that even in this case hydrogen is still the main product. The non-trivial details of polarization losses and other cell dependent non-idealities have been modelled in detail for PEC-based $\mathrm{CO}_{2}$ reducing cells. 26,27

\section{Multi-step electrochemical reduction}

The reversible potential for converting $\mathrm{CO}\left(\right.$ and $\mathrm{H}_{2} \mathrm{O}$ ) to any hydrocarbon or oxygenate fuel molecule is lower $\left(\mathrm{U}_{\text {std }} \sim 1000 \mathrm{mV}\right)$ than for converting $\mathrm{CO}_{2}$ to $\mathrm{CO}\left(\mathrm{U}_{\text {std }}=1.33 \mathrm{~V}\right)$. This means that a mono-functional electrocatalyst which reduces $\mathrm{CO}_{2}$ step by step (via $\mathrm{CO}$ ) to e.g. $\mathrm{CH}_{4}$ will have its thermodynamic efficiency limited by the (most) demanding step.

In order for the process to run at the thermodynamic equilibrium potential the system must bind all intermediates just right so that every electron transfer step may take place at the equilibrium potential. However, in general, the binding energies of chemically similar intermediates scale linearly with each other on any given site making it impossible for a simple mono-functional

electrocatalyst to bind everything just right. ${ }^{28-30}$ As an illustration we consider the reaction $\mathrm{CO}_{2}$ $+2 \mathrm{H}_{2} \mathrm{O} \rightarrow \mathrm{CH}_{4}+2 \mathrm{O}_{2}, \mathrm{z}=8, \Delta \mathrm{G}=817.8 \mathrm{~kJ} / \mathrm{mol}$. All 8 electrons must be supplied at (at least) the reversible potential of the most thermodynamically demanding step for all steps to be downhill. If we assume that the process goes via free CO (as an example) that makes the total energy requirement, $E_{\text {ideal }}=8 \mathrm{e} \times 1.33 \mathrm{~V}=10.64 \mathrm{eV}$, (assuming zero overpotential for the $\mathrm{CO}$ step). However, $\Delta \mathrm{G}=817.8 \mathrm{~kJ} / \mathrm{mol}$ which only corresponds to $\mathrm{E}_{\text {rev }}=8.48 \mathrm{eV}$. Hence even with zero overpotential for both oxygen evolution and for $\mathrm{CO}_{2}$ reduction such a system would still be 
limited to an electrolysis efficiency of $8.48 \mathrm{eV} / 10.64 \mathrm{eV}=0.797$ (due to too weak binding of the CO intermediate). The limit for other fuels like ethanol would be similar.

In order to circumvent this limitation, the reduction process may be broken up into (at least) two steps: A first step where $\mathrm{CO}_{2}$ is reduced to $\mathrm{CO}$, with a reversible thermodynamic potential of $\mathrm{U}_{\text {std }}$ $=1.33 \mathrm{~V}$; and subsequent step(s) where $\mathrm{CO}$ is reduced further - in the example to $\mathrm{CH}_{4}$, for which $\mathrm{U}_{\text {std }}=0.97 \mathrm{~V}$. In this case, the overall efficiency becomes $(2 \times 1.33 \mathrm{~V}+6 \times 0.97 \mathrm{~V}) / 8.48 \mathrm{~V}=1.0$, i.e. there is no fundamental efficiency limitation beyond the practical problems with real-world overpotentials, etc.

The benefit of breaking the $\mathrm{CO}_{2}$ reduction process into a $\mathrm{CO}_{2} \rightarrow \mathrm{CO}$ step and a separate $\mathrm{CO} \rightarrow$ fuel step is not only thermodynamic. It also introduces the option to run the 2-electron steps on different catalysts, in different electrolytes and under different conditions (pressure, $\mathrm{pH}$, temperature, current density, etc.). One could even envision a separate process for each 2electron step - i.e. separate electrolyzers/PEC cells for $\mathrm{CO}_{2} \rightarrow \mathrm{CO}, \mathrm{CO} \rightarrow$ formaldehyde, formaldehyde $\rightarrow$ methanol, and methanol $\rightarrow$ methane. For this reason, this work will focus on $2 \mathrm{e}^{-}$ $\mathrm{CO}_{2}$ reduction reactions for PEC. The goal here is to model the realistically achievable Solar-ToFuel (STF)-efficiency for two such reaction products (CO and formate) based on published experimental $\mathrm{CO}_{2}$-reduction current-voltage data. This entails that we exclusively consider electrocatalysts, which make CO or formate with a high faradaic selectivity (better than 80\%) and at reasonable PEC-relevant current densities (at least $10 \mathrm{~mA} / \mathrm{cm}^{2}$ ). This rules out many CO2 reduction catalysts, since they either have poor selectivity or current density. ${ }^{31,32}$ 


\section{Photoelectrochemical CO synthesis}

We now consider PEC-driven synthesis of carbon monoxide, which is a promising alternative to water splitting. Like $\mathrm{H}_{2}$, $\mathrm{CO}$ is an energetic gaseous compound and an important industrial chemical (in "syngas"). ${ }^{33} \mathrm{CO}$, like $\mathrm{H}_{2}$, is a 2-electron reduction product from its parent compound and on a per electron basis $\mathrm{CO}\left(\mathrm{U}_{\text {std }}=1.33 \mathrm{~V}\right)$ carries $8 \%$ more energy than $\mathrm{H}_{2}\left(\mathrm{U}_{\text {std }}=\right.$ 1.23 V). As a fuel, however, $\mathrm{CO}$ is impractical (a poisonous gas with a low gravimetric energy density). Recent research, however, has shown that CO may be further reduced electrochemically to practical liquid fuels such as ethanol. ${ }^{34}$

The overall reaction is:

$\mathrm{CO}_{2} \rightarrow \mathrm{CO}+1 / 2 \mathrm{O}_{2} \quad\left(\mathrm{z}=2, \mathrm{U}_{\mathrm{std}}=1.33 \mathrm{~V}\right)$

In 2012 Chen et al. reported that this reaction may run with a faradaic selectivity of almost 100\% and at low overpotential on oxide-derived Au. ${ }^{35}$ At current densities below $2 \mathrm{~mA} / \mathrm{cm}^{2}$ the measured Tafel slope is only $56 \mathrm{mV} /$ decade. Above $2 \mathrm{~mA} / \mathrm{cm}^{2}$ mass transport limitations kick in, which gives a higher effective Tafel slope. ${ }^{35}$ For this reason we consider two different situations based on Chen's catalyst: One (optimistic) where we assume that clever device design may overcome mass transport issues and simply extrapolate low current behavior ( 175 mV overvoltage at $1 \mathrm{~mA} / \mathrm{cm}^{2}$ and $56 \mathrm{mV} /$ decade Tafel slope). The other (pessimistic), where we use the reported I-V data as is - assuming no improvements mass transport. Modestino et al. have shown that even modest electrolyte recirculation or agitation may almost eliminate concentration gradients in the electrolyte, so there is hope that the extrapolated case may not be unrealistic in a real device. ${ }^{36}$ As per our standard conditions (Table 1 ) we model OER via conservative parameters: (320 mV overpotential at $1 \mathrm{~mA} / \mathrm{cm}^{2}$ and a Tafel slope of $40 \mathrm{mV} /$ decade) which is easily achieved by existing OER catalysts. ${ }^{37-39}$ We also assume an electrolyte layer above the 
device with an optical thickness equivalent to $2 \mathrm{~cm}$ of water. For the simulation we further assume a loss of $10 \%$ of incident light (reflections, etc.) and that the tandem solar cells are both quite good with a dark saturation current only 100x the theoretical minimum and that shunt or series resistance losses (beyond that of the electrolyte as mentioned above) are almost negligible. These assumptions are consistent with our previous work on water splitting ${ }^{13}$, are deliberately conservative so as to be realizable in practice. The electrolyte reported by Chen et al. ${ }^{35}$ is $\mathrm{CO}_{2}$ saturated $0.5 \mathrm{M} \mathrm{KHCO}_{3}$ for which the conductivity is assumed to be $38.8 \mathrm{mS} / \mathrm{cm}$ at $298 \mathrm{~K}$ and we model ionic resistance with a $0.5 \mathrm{~cm}$ effective ionic path length (which is taken to include the resistance of a possible membrane). ${ }^{40}$

The WBM program ${ }^{13}$ finds the photocurrent density for every point on the grid and calculates the STF-efficiency - in this case it is Solar-to-Carbon monoxide - as:

$S T F=1.33 \mathrm{~V} \times \frac{\text { photocurrent density }}{\text { incident solar irradiance }}$

$\mathrm{CO}_{2}$ to $\mathrm{CO}$

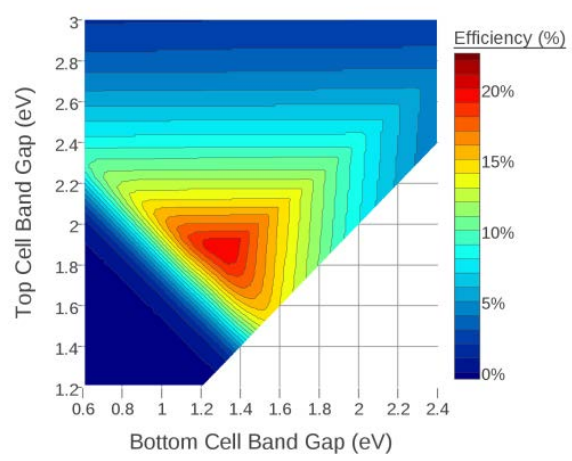

A

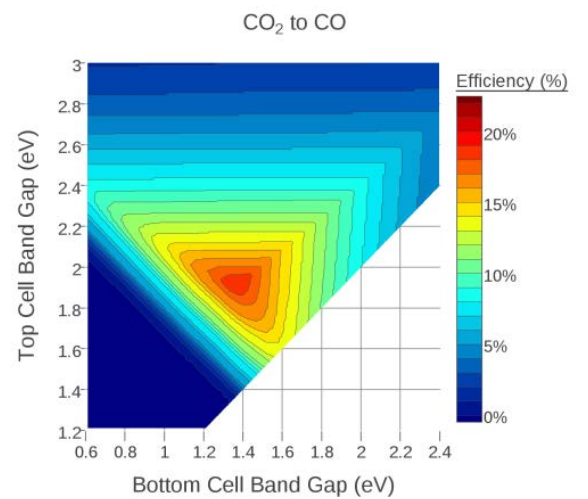

B

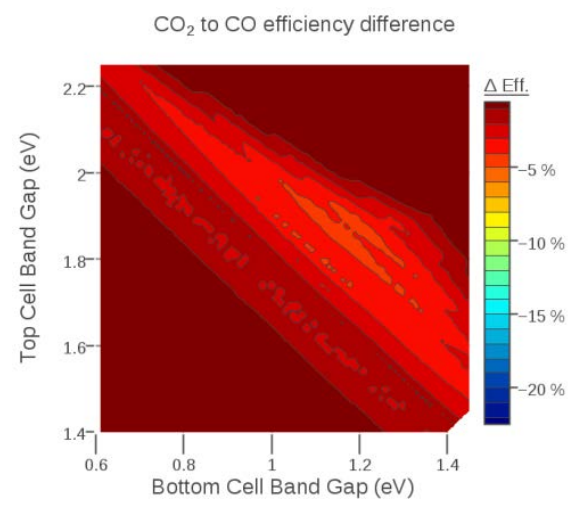

C

Figure 1 Solar-to-fuel efficiency for $\mathrm{CO}$ production as a function of the band gaps of the top and bottom photoabsorber using experimental I-V data for $\mathrm{CO}_{2}$ reduction ${ }^{35}$. (A): Extrapolated Tafel $\mathrm{CO}_{2}$ reduction current (optimistic case). Peak STF efficiency: $\mathbf{2 0 . 0 \%}$ $(1.32 \mathrm{eV}, 1.89 \mathrm{eV})$. (B): Raw, as-reported $\mathrm{CO}_{2}$ reduction I-V data ${ }^{35}$. Peak STF efficiency: 
$19.0 \%(1.38 \mathrm{eV}, 1.92 \mathrm{eV})$. (C): Difference plot (A-B) showing that a maximum STF efficiency loss of $4.5 \%$ in the voltage-constrained part of the plot, while near the optimum band-gap range, the loss is only $\sim 1 \%$ as indicated in (A) and (B). Standard conditions (Table 1) are assumed. Photon matching of the top- and bottom absorber is assumed.

The results for the two cases are shown in Figure 1. The extrapolated case reaches an ST-CO efficiency of $20.0 \%$ while using the raw, measured I-V data ${ }^{35}$ without extrapolation yields an ST-CO efficiency of $19.0 \%$.

Photoelectrochemical formate/formic acid

Much like CO, formic acid is a useful product which is used industrially to preserve animal feeds and treat leather as well as a chemical feedstock, but it is possible, that it could serve as an intermediate for further reduction to solar fuels in the future. In 2015 Min and Kanan reported efficient reduction of $\mathrm{CO}_{2}$ to formate over Pd nanoparticles ${ }^{41}$, and in early 2016 Gao et al. published that a partially oxidized ultrathin cobalt layer may reduce $\mathrm{CO}_{2}$ to formate at current densities above $10 \mathrm{~mA} / \mathrm{cm}^{2}$ and with a high faradaic selectivity $~ 90 \% .{ }^{42}$ Since formate seems to be a viable alternative to $\mathrm{CO}$ as a 2-electron reduction product, we present the PEC analysis for formate synthesis based on Gao's catalyst here. The reaction in this electrolyte is:

$\mathrm{CO}_{2}+\mathrm{H}_{2} \mathrm{O} \rightarrow \mathrm{HCOO}^{-}+1 / 2 \mathrm{O}_{2}+\mathrm{H}^{+}\left(\mathrm{z}=2, \mathrm{U}_{\mathrm{std}}=1.41 \mathrm{~V}\right)$.

The electrolyte in this case is $\mathrm{CO}_{2}$ saturated $0.1 \mathrm{M} \mathrm{Na}_{2} \mathrm{SO}_{4}(\mathrm{pH} \approx 6)$ for which we estimate a conductivity of $18.0 \mathrm{mS} / \mathrm{cm}$ at $298 \mathrm{~K} .{ }^{40}$ The analysis is conducted by assuming an overvoltage at $1 \mathrm{~mA} / \mathrm{cm}^{2}$ of $140 \mathrm{mV}$ and a Tafel slope of $44 \mathrm{mV} /$ decade. This is based on slight extrapolation of the reported electrocatalysts performance ${ }^{42}$ to $\sim 14 \mathrm{~mA} / \mathrm{cm}^{2}$ (experimental data is available up to $\sim 10 \mathrm{~mA} / \mathrm{cm}^{2}$ so the extrapolation is small) which turns out to be the maximum current relevant 
for PEC. We assume that although Gao et al. achieved a 90\% faradaic efficiency, optimizations should be able to bring this to nearly $100 \%$ faradaic efficiency. ${ }^{42}$ The other assumptions about the device are all the same the same as in the CO case. The STF efficiency is calculated as:

$$
S T F=1.41 \mathrm{~V} \times \frac{\text { photocurrent density }}{\text { incident solar irradiance }}
$$

The result is shown in Figure 2.

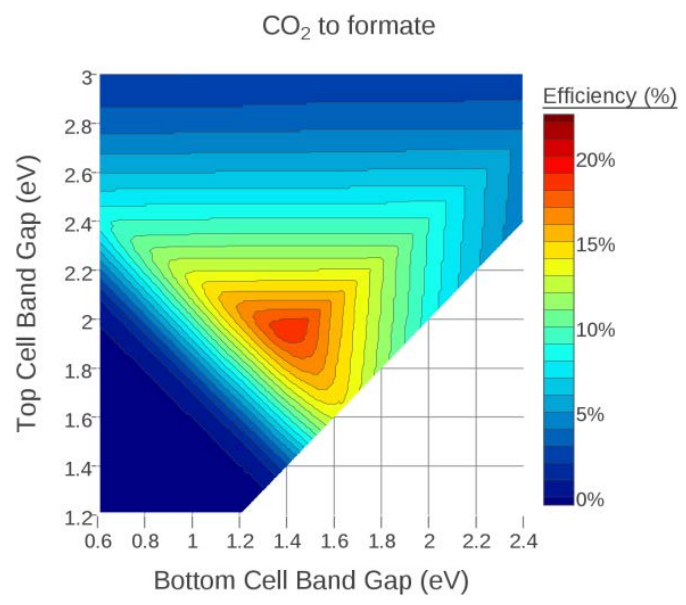

Figure 2 Solar-to-fuel efficiency for $\mathrm{CO}_{2}$ reduction to formate as a function of the band gaps of the top and bottom photoabsorber using experimental $\mathrm{I}-\mathrm{V}$ data for $\mathrm{CO}_{2}$ reduction ${ }^{42}$. Peak STF efficiency: $18.8 \%(1.42 \mathrm{eV}, 1.96 \mathrm{eV})$. Standard conditions (Table 1) are assumed. Photon matching of the top- and bottom absorber is assumed.

\section{Discussion}

The standard conditions in common for all models in this work (Table 1) are chosen by the authors with realism in mind. We note that the STF efficiencies change comparatively little (< $1 \%$ abs) upon adjusting any single the parameters within a reasonable range. The exceptions to this (besides the trivial change in STF due to changing the optical light loss or the faradaic efficiency) are: 1) decreasing the shunt resistance or 2) increasing the ionic resistance. A table 
showing parameter sensitivities is included in the supplementary material and the WBM tool is freely available on-line to simulate arbitrary parameters.

With the present state-of-the-art catalysts, the three 2-electron products considered $\left(\mathrm{H}_{2}, \mathrm{CO}\right.$ and $\mathrm{HCOOH}$ ) all theoretically reach essentially the same maximum PEC-driven STF efficiency limit. Viz. for a device design where there is $2 \mathrm{~cm}$ of water above the top absorber, but without ohmic losses in the electrolyte, all three reactions may reach a maximum STF efficiency of $22.2 \%+-$ $0.5 \%$, but formate is the winner by a small margin. (STH: $21.8 \%$, ST-CO: $21.8 \%$, ST-Formate: 22.7\%) This result is remarkable since the three reactions have different standard potentials (1.23 $\mathrm{V}, 1.33 \mathrm{~V}$ and $1.41 \mathrm{~V}$ respectively), in particular since hydrogen evolution over a platinum catalyst has a substantial $\sim 180 \mathrm{mV}$ overpotential advantage in comparison to the $\mathrm{CO}_{2}$ reduction to $\mathrm{CO}$ on oxide derived $\mathrm{Au}$ and a $\sim 130 \mathrm{mV}$ advantage compared to $\mathrm{CO}_{2}$ reduction to formate over 4-atom Co-layers. The reason that the carbon-containing 2-electron products are competitive from an STF efficiency point of view, despite their significant overpotential disadvantage, is that a tuned tandem system only suffers a minor drop in photocurrent density (from $17.5 \mathrm{~mA} / \mathrm{cm}^{2}$ to $16.1 \mathrm{~mA} / \mathrm{cm}^{2}$ ) as the operating point is increased from $\sim 1660 \mathrm{mV}$ (water splitting) to $\sim 1980 \mathrm{mV}$ (formate production). This drop in photocurrent is compensated by the increasing energy content (per electron) of the formate or CO products so the overall result is a similar STF efficiency. In fact, if a $\mathrm{CO}_{2}$ reduction catalyst existed, which could make either $\mathrm{CO}$ or formate at overpotentials similar to HER on Pt (in 2015 such a catalyst was reported for formate ${ }^{41}$ and very recently it showed great performance in PEC application ${ }^{43}$ ), $\mathrm{CO}_{2}$ reduction could reach higher STF efficiency than water splitting. This is illustrated in Figure 3, which shows the ideal performance under conditions of zero electrochemical losses, but otherwise 
standard conditions (Table 1). Clearly, a tandem absorber system is best suited for operating at a voltage in the $1800 \mathrm{mV}$ - $2400 \mathrm{mV}$ range - i.e. where the anode-cathode potential difference under real conditions is in this range. A water splitting cell, which has a realistic operating voltage of $1660 \mathrm{mV}$ to be delivered by the photoabsorber(s), therefore misses the efficiency peak of a tandem system by about $200 \mathrm{mV}$ whereas $\mathrm{CO}$ and formate production operating at $1900 \mathrm{mV}$ to $2000 \mathrm{mV}$ are much closer efficiency peak of a tandem system.

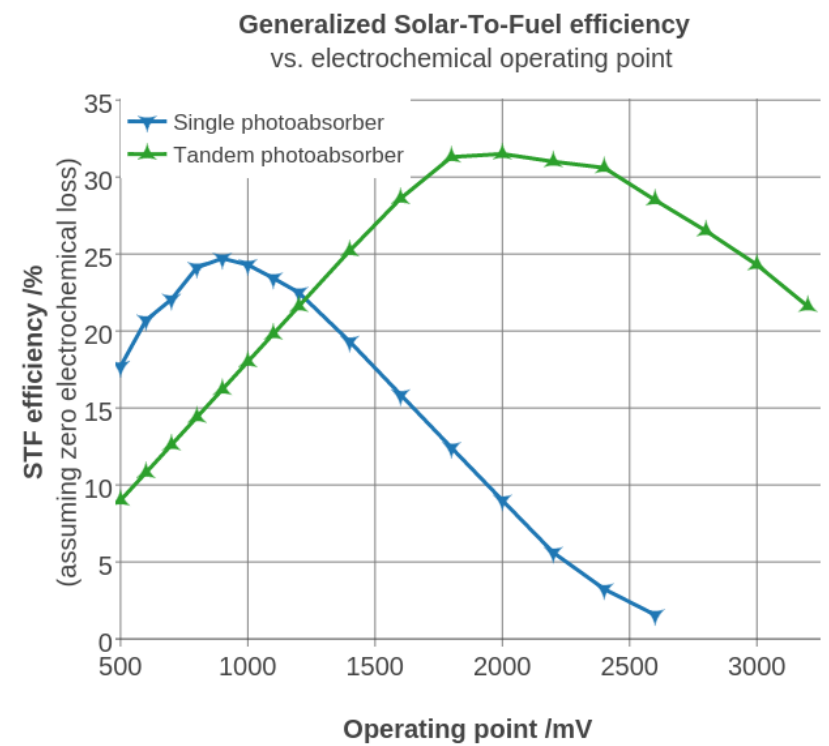

Figure 3 General comparison of maximum Solar-To-Fuel efficiency as a function of the operating point (equilibrium potential) of the device. Electrochemical losses are set to be zero, but otherwise standard conditions (Table 1) are assumed for the photoabsorbers. The operating point for water splitting is $\sim 1660 \mathrm{mV}$ while it is $\sim 1980 \mathrm{mV}$ for formate production.

When ionic losses in the membrane and electrolyte are included (via $0.5 \mathrm{~cm}$ of effective electrolyte thickness in the model), as was the cases considered in Figure 1 \& Figure 2, the picture becomes more favorable for water splitting because the $\mathrm{CO}_{2}$ reduction electrolytes have 
reduced conductivity compared to the water splitting case. While the water splitting efficiency drops $0.4 \%$ abs due to the addition of ionic resistance voltage loss (maximum STH efficiency of $21.4 \%$ ), in the ST-CO case the efficiency drops $1.8 \%_{\text {abs }}$ to $20.0 \%$ (Figure 1), and in the STformate case the efficiency drops $3.9 \%$ abs to $18.8 \%$ (Figure 2, Figure 4) based on the electrolyte conductances of the reported $\mathrm{CO}_{2}$ reduction systems.
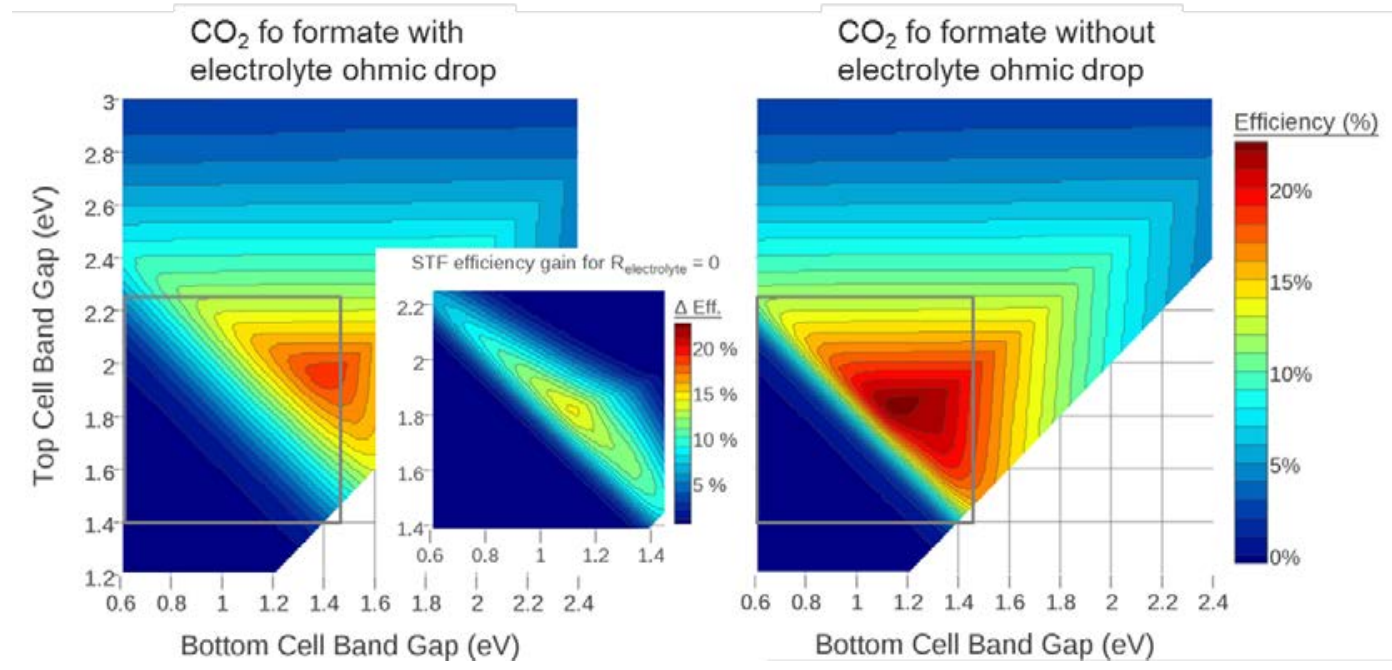

Figure 4 Comparison of solar-to-fuel efficiency for $\mathrm{CO}_{2}$ reduction to formate comparing the simulated performance including electrolyte potential drop (left) (see also Figure 2 for a clean version of the same graph) with a simulation without electrolyte potential drop (right). The STF efficiency increases from $18.8 \%$ to $22.7 \%$ at the optimum bandgap combination if electrolyte potential drop is eliminated. The difference plot (center) shows that for a low-bandgap tandem $(1.15 \mathrm{eV}, 1.8 \mathrm{eV})$, the STF efficiency gain can be up to $14 \%$ abs by eliminating the electrolyte potential drop. Standard conditions (Table 1) are assumed. Photon matching of the top- and bottom absorber is assumed.

This effect underscores the disadvantage of moderate $\mathrm{pH}$ electrolytes and the need for clever device designs, e.g. using bipolar membranes ${ }^{44,45}$ to enable use of high ionic strength electrolytes ${ }^{43}$ and minimize ionic resistance. 
Compared to the 2-electron products, all of the more reduced products currently seem impractical to make. The present state-of-the-art copper electrocatalyst can be tweaked to give a combined faradaic yield of $\mathrm{C}_{2}$-products ethylene, ethanol and ethane (likely via a common acetaldehyde intermediate ${ }^{46}$ ) of approximately 55\%. ${ }^{34,47}$ The low selectivity of $\mathrm{Cu}$ and $\mathrm{Ag}$ electrocatalysts leave much to be desired. ${ }^{48,49}$ Even using cationic selectivity tuning $\mathrm{C}_{2+}$ products make up no more than half the faradaic current ${ }^{50}$, and when the corresponding overpotential of roughly $1000 \mathrm{mV}$ for reasonable current densities is also considered, it becomes clear that the technology to go beyond the 2-electron products is not yet sufficiently mature to be a viable option for a PEC device. For example, if the overall voltage requirement is increased from $2.0 \mathrm{~V}$ to $3.0 \mathrm{~V}$ the maximum efficiency drops from $\sim 31.5 \%$ abs to less than $\sim 24 \%$ abs (Figure 3 ) - i.e. a significant $24 \%$ relative loss. Clearly, new electrocatalysts with significantly lower overpotential and much higher selectivity are needed in order to make $4 \mathrm{e}^{-}, 8 \mathrm{e}^{-}$, and $12 \mathrm{e}^{-}$-solar fuels viable via PEC. The basic problem, however, is that the scaling relations which govern electrochemical $\mathrm{CO}_{2}$ hydrogenation essentially preclude overpotentials below $\sim 600 \mathrm{mV}{ }^{22,51}$ The key to more reduced products, therefore, is to find catalysts, which are bi-functional or otherwise may break free of the scaling relations and enable lower overpotentials. PEC-based solar fuel synthesis should become increasingly attractive as improved electrocatalysts hopefully become available in the future, although comprehensive technoeconomic analysis similar to what has appeared for solar hydrogen ${ }^{16}$ has not yet appeared for PEC-based $\mathrm{CO}_{2}$ reduction.

At present, PEC-based CO- (or formate) synthesis is very promising since there are good thermodynamic arguments why these products make sense as intermediates in solar fuel synthesis and since selective catalysts for these reactions have appeared in the last few years and 
a PEC based formate-producing cell was demonstrated very recently. ${ }^{43}$ PEC may finally be about other reactions than only water splitting.

\section{ACKNOWLEDGEMENT}

The authors acknowledge support from the Danish Council for Independent Research (DFF4005-00463), and support from the VILLUM Center for Science of Sustainable Fuels and Chemicals.

\section{REFERENCES}

(1) Vesborg, P. C. K.; Seger, B.; Chorkendorff, I. Recent Development in Hydrogen Evolution Reaction Catalysts and Their Practical Implementation. J Phys Chem Lett 2015, 6, 951-957.

(2) McCrory, C. C. L.; Jung, S.; Ferrer, I. M.; Chatman, S. M.; Peters, J. C.; Jaramillo, T. F. Benchmarking Hydrogen Evolving Reaction and Oxygen Evolving Reaction Electrocatalysts for Solar Water Splitting Devices. J. Am. Chem. Soc. 2015, 137, 43474357.

(3) Walter, M. G.; Warren, E. L.; McKone, J. R.; Boettcher, S. W.; Mi, Q.; Santori, E. A.; Lewis, N. S. Solar Water Splitting Cells. Chem. Rev. 2010, 110, 6446-6473.

(4) Seger, B.; Castelli, I. E.; Vesborg, P. C. K.; Jacobsen, K. W.; Hansen, O.; Chorkendorff, I. 2-Photon Tandem Device for Water Splitting: Comparing Photocathode First versus Photoanode First Designs. Energy Environ. Sci. 2014, 7, 2397-2413.

(5) Weber, M.; Dignam, M. Splitting Water with Semiconducting photoelectrodesEfficiency Considerations. Int. J. Hydrogen Energy 1986, 11, 225-232.

(6) Rocheleau, R.; Miller, E. L. Photoelectrochemical Production of Hydrogen: Engineering 
Loss Analysis. Int. J. Hydrogen Energy 1997, 22, 771-782.

(7) Hu, S.; Xiang, C.; Haussener, S.; Berger, A. D.; Lewis, N. S. An Analysis of the Optimal Band Gaps of Light Absorbers in Integrated Tandem Photoelectrochemical WaterSplitting Systems. Energy Environ. Sci. 2013, 6, 2984-2993.

(8) Seitz, L. C.; Chen, Z.; Forman, A. J.; Pinaud, B. a.; Benck, J. D.; Jaramillo, T. F. Modeling Practical Performance Limits of Photoelectrochemical Water Splitting Based on the Current State of Materials Research. ChemSusChem 2014, 7, 1372-1385.

(9) Döscher, H.; Geisz, J. F.; Deutsch, T. G.; Turner, J. A. Sunlight Absorption in Water Efficiency and Design Implications for Photoelectrochemical Devices. Energy Environ. Sci. 2014, 7, 2951-2956.

(10) Walczak, K.; Chen, Y.; Karp, C.; Beeman, J. W.; Shaner, M.; Spurgeon, J.; Sharp, I. D.; Amashukeli, X.; West, W.; Jin, J.; et al. Modeling, Simulation, and Fabrication of a Fully Integrated, Acidstable, Scalable Solar-Driven Water-Splitting System. ChemSusChem 2015, 8, 544-551.

(11) Chen, Z.; Jaramillo, T. F.; Deutsch, T. G.; Kleiman-Shwarsctein, A.; Forman, A. J.; Gaillard, N.; Garland, R.; Takanabe, K.; Heske, C.; Sunkara, M.; et al. Accelerating Materials Development for Photoelectrochemical Hydrogen Production: Standards for Methods, Definitions, and Reporting Protocols. J. Mater. Res. 2010, 25, 3-16.

(12) Dumortier, M.; Tembhurne, S.; Haussener, S. Holistic Design Guidelines for Solar Hydrogen Production by Photo-Electrochemical Routes. Energy Environ. Sci. 2015, 8, 3614-3628.

(13) Seger, B.; Hansen, O.; Vesborg, P. C. K. A Flexible Web-Based Approach to Modeling Tandem Photocatalytic Devices. submitted 2016. 
(14) Haussener, S.; Hu, S.; Xiang, C.; Weber, A. Z.; Lewis, N. S. Simulations of the Irradiation and Temperature Dependence of the Efficiency of Tandem Photoelectrochemical WaterSplitting Systems. Energy I\& Environ. Sci. 2013, 6, 3605.

(15) Dumortier, M.; Haussener, S. Design Guidelines for Concentrated Photo-Electrochemical Water Splitting Devices Based on Energy and Greenhouse Gas Yield Ratios. Energy Environ. Sci. 2015, 3069-3082.

(16) Pinaud, B. A.; Benck, J. D.; Seitz, L. C.; Forman, A. J.; Chen, Z.; Deutsch, T. G.; James, B. D.; Baum, K. N.; Baum, G. N.; Ardo, S.; et al. Technical and Economic Feasibility of Centralized Facilities for Solar Hydrogen Production via Photocatalysis and Photoelectrochemistry. Energy Environ. Sci. 2013, 6, 1983.

(17) Sathre, R.; Scown, C. D.; Morrow, W. R.; Stevens, J. C.; Sharp, I. D.; Ager, J. W.; Walczak, K.; Houle, F. A.; Greenblatt, J. B. Life-Cycle Net Energy Assessment of LargeScale Hydrogen Production via Photoelectrochemical Water Splitting. Energy Environ. Sci. 2014, 7, 3264-3278.

(18) Osterloh, F. E. The Low Concentration of CO 2 in the Atmosphere Is an Obstacle to a Sustainable Artificial Photosynthesis Fuel Cycle Based on Carbon. ACS Energy Lett. 2016, 1060-1061.

(19) Parkinson, B. Advantages of Solar Hydrogen Compared to Direct Carbon Dioxide Reduction for Solar Fuel Production. ACS Energy Lett. 2016, 1057-1059.

(20) Tatin, A.; Bonin, J.; Robert, M. A Case for Electrofuels. ACS Energy Lett. 2016, 10621064.

(21) Hori, Y.; Wakebe, H.; Tsukamoto, T.; Koga, O. Electrocatalytic Process of CO Selectivity in Electrochemical Reduction of CO2 at Metal Electrodes in Aqueous Media. 
Electrochim. Acta 1994, 39, 1833-1839.

(22) Jovanov, Z. P.; Hansen, H. A.; Varela, A. S.; Malacrida, P.; Peterson, A. A.; Nørskov, J. K.; Stephens, I. E. L.; Chorkendorff, I. Opportunities and Challenges in the Electrocatalysis of CO2 and CO Reduction Using Bifunctional Surfaces: A Theoretical and Experimental Study of Au-Cd Alloys. J. Catal. 2016.

(23) Liu, C.; Colon, B. C.; Ziesack, M.; Silver, P. A.; Nocera, D. G. Water SplittingBiosynthetic System with CO2 Reduction Efficiencies Exceeding Photosynthesis. Science (80-. ). 2016, 352, 1210-1213.

(24) Rongé, J.; Bosserez, T.; Martel, D.; Nervi, C.; Boarino, L.; Taulelle, F.; Decher, G.; Bordiga, S.; Martens, J. A. Monolithic Cells for Solar Fuels. Chem. Soc. Rev. 2014, 43, 7963-7981.

(25) Singh, M. R.; Clark, E. L.; Bell, A. T. Thermodynamic and Achievable Efficiencies for Solar-Driven Electrochemical Reduction of Carbon Dioxide to Transportation Fuels. Proc. Natl. Acad. Sci. 2015, 201519212.

(26) Gutierrez, R. R.; Haussener, S. Modeling of Concurrent CO 2 and Water Splitting by Practical Photoelectrochemical Devices. J. Electrochem. Soc. 2016, 163, H1008-H1018.

(27) Singh, M. R.; Clark, E. L.; Bell, A. T. Effects of Electrolyte, Catalyst, and Membrane Composition and Operating Conditions on the Performance of Solar-Driven Electrochemical Reduction of Carbon Dioxide. Phys. Chem. Chem. Phys. 2015, 17, 18924-18936.

(28) Abild-Pedersen, F.; Greeley, J.; Studt, F.; Rossmeisl, J.; Munter, T. R.; Moses, P. G.; Skúlason, E.; Bligaard, T.; Nørskov, J. K. Scaling Properties of Adsorption Energies for Hydrogen-Containing Molecules on Transition-Metal Surfaces. Phys. Rev. Lett. 2007, 99. 
(29) Medford, A. J.; Vojvodic, A.; Hummelshøj, J. S.; Voss, J.; Abild-Pedersen, F.; Studt, F.; Bligaard, T.; Nilsson, A.; Nørskov, J. K. From the Sabatier Principle to a Predictive Theory of Transition-Metal Heterogeneous Catalysis. J. Catal. 2015, 328, 36-42.

(30) Peterson, A. a.; Abild-Pedersen, F.; Studt, F.; Rossmeisl, J.; Nørskov, J. K. How Copper Catalyzes the Electroreduction of Carbon Dioxide into Hydrocarbon Fuels. Energy Environ. Sci. 2010, 3, 1311.

(31) White, J. L.; Baruch, M. F.; Pander III, J. E.; Hu, Y.; Fortmeyer, I. C.; Park, J. E.; Zhang, T.; Liao, K.; Gu, J.; Yan, Y.; et al. Light-Driven Heterogeneous Reduction of Carbon Dioxide: Photocatalysts and Photoelectrodes. Chem. Rev. 2015, 115, 12888-12935.

(32) Watkins, J. D.; Bocarsly, A. B. Direct Reduction of Carbon Dioxide to Formate in HighGas-Capacity Ionic Liquids at Post-Transition-Metal Electrodes. ChemSusChem 2014, 7, 284-290.

(33) Dry, M. E. Handbook of Heterogeneous Catalysis; Ertl, G.; Knözinger, H.; Schüth, F.; Weitkamp, J., Eds.; Wiley-VCH Verlag GmbH \& Co. KGaA: Weinheim, Germany, 2008.

(34) Li, C. W.; Ciston, J.; Kanan, M. W. Electroreduction of Carbon Monoxide to Liquid Fuel on Oxide-Derived Nanocrystalline Copper. Nature 2014, 508, 504-507.

(35) Chen, Y.; Li, C. W.; Kanan, M. W. Aqueous CO 2 Reduction at Very Low Overpotential on Oxide-Derived Au Nanoparticles. J. Am. Chem. Soc. 2012, 134, 19969-19972.

(36) Modestino, M. a.; Walczak, K. a.; Berger, A.; Evans, C. M.; Haussener, S.; Koval, C.; Newman, J. S.; Ager, J. W.; Segalman, R. a. Robust Production of Purified H 2 in a Stable, Self-Regulating, and Continuously Operating Solar Fuel Generator. Energy Environ. Sci. 2014, 7, 297-301.

(37) McCrory, C. C. L.; Jung, S.; Peters, J. C.; Jaramillo, T. F. Benchmarking Heterogeneous 
Electrocatalysts for the Oxygen Evolution Reaction. J. Am. Chem. Soc. 2013, 135, 1697716987.

(38) Lodi, G.; Sivieri, E.; De Battisti, A.; Trasatti, S. Ruthenium Dioxide-Based Film Electrodes - III. Effect of Chemical Composition and Surface Morphology on Oxygen Evolution in Acid Solutions. J. Appl. Electrochem. 1978, 8, 135-143.

(39) Trotochaud, L.; Young, S. L.; Ranney, J. K.; Boettcher, S. W. Nickel-Iron Oxyhydroxide Oxygen-Evolution Electrocatalysts: The Role of Intentional and Incidental Iron Incorporation. J. Am. Chem. Soc. 2014, 136, 6744-6753.

(40) Vanysek, P. Equivalent Conductivity of Electrolytes in Aqueous Solution. In CRC Handbook of Chemistry and Physics; Haynes, W. M., Ed.; pp. 5-74.

(41) Min, X.; Kanan, M. W. Pd-Catalyzed Electrohydrogenation of Carbon Dioxide to Formate: High Mass Activity at Low Overpotential and Identification of the Deactivation Pathway. J. Am. Chem. Soc. 2015, 137, 4701-4708.

(42) Gao, S.; Lin, Y.; Jiao, X.; Sun, Y.; Luo, Q.; Zhang, W.; Li, D.; Yang, J.; Xie, Y. Partially Oxidized Atomic Cobalt Layers for Carbon Dioxide Electroreduction to Liquid Fuel. Nature 2016, 529, 68-71.

(43) Zhou, X.; Liu, R.; Sun, K.; Chen, Y.; Verlage, E.; Francis, sonja A.; Lewis, N. S.; Xiang, C. Solar-Driven Reduction of 1 Atm of CO 2 to Formate at 10\% Energy-Conversion Efficiency by Use of a TiO 2 -Protected III-V Tandem Photoanode in Conjunction with a Bipolar Membrane and a Pd/C Cathode. ACS Energy Lett. 2016, 1, 764-770.

(44) Luo, J.; Vermaas, D. A.; Bi, D.; Hagfeldt, A.; Smith, W. A.; Grätzel, M. Bipolar Membrane-Assisted Solar Water Splitting in Optimal pH. Adv. Energy Mater. 2016, 6, 1600100. 
(45) Sun, K.; Liu, R.; Chen, Y.; Verlage, E.; Lewis, N. S.; Xiang, C. A Stabilized, Intrinsically Safe, 10\% Efficient, Solar-Driven Water-Splitting Cell Incorporating Earth-Abundant Electrocatalysts with Steady-State pH Gradients and Product Separation Enabled by a Bipolar Membrane. Adv. Energy Mater. 2016, 6, 1600379.

(46) Bertheussen, E.; Verdaguer-Casadevall, A.; Ravasio, D.; Montoya, J. H.; Trimarco, D. B.; Roy, C.; Meier, S.; Wendland, J.; Nørskov, J. K.; Stephens, I. E. L.; et al. Acetaldehyde as an Intermediate in the Electroreduction of Carbon Monoxide to Ethanol on Oxide-Derived Copper. Angew. Chemie Int. Ed. 2016, 55, 1450-1454.

(47) Ren, D.; Deng, Y.; Handoko, A. D.; Chen, C. S.; Malkhandi, S.; Yeo, B. S. Selective Electrochemical Reduction of Carbon Dioxide to Ethylene and Ethanol on Copper(I) Oxide Catalysts. ACS Catal. 2015, 5, 2814-2821.

(48) Kuhl, K. P.; Cave, E. R.; Abram, D. N.; Jaramillo, T. F. New Insights into the Electrochemical Reduction of Carbon Dioxide on Metallic Copper Surfaces. Energy Environ. Sci. 2012, 5, 7050.

(49) Chen, Y.; Lewis, N. S.; Xiang, C. Modeling and Simulation of the Spatial and LightIntensity Dependence of Product Distributions in an Integrated Photoelectrochemical CO 2 Reduction System. ACS Energy Lett. 2016, 1, 273-280.

(50) Singh, M. R.; Kwon, Y.; Lum, Y.; Ager, J. W.; Bell, A. T. Hydrolysis of Electrolyte Cations Enhances the Electrochemical Reduction of CO 2 over Ag and Cu. J. Am. Chem. Soc. 2016, 138, 13006-13012.

(51) Hansen, H. A.; Shi, C.; Lausche, A.; Peterson, A.; Nørskov, J. K. Bifunctional Alloys for the Electroreduction of $\mathrm{CO}_{2}$ and CO. Phys. Chem. Chem. Phys. 2016, 9194-9201. 


\section{Supplementary information}

Parameter sensitivity

\begin{tabular}{|c|c|c|c|}
\hline & Optimistic & Standard & Pessimistic \\
\hline Temperature & $\begin{array}{l}273 \mathrm{~K} \\
+0.5 \%\end{array}$ & 298K & $\begin{array}{l}323 \mathrm{~K} \\
-0.8 \%\end{array}$ \\
\hline Optical water thickness & $\begin{array}{l}1 \mathrm{~cm} \\
+0.2 \%\end{array}$ & $2 \mathrm{~cm}$ & $\begin{array}{l}3 \mathrm{~cm} \\
-0.1 \%\end{array}$ \\
\hline Dark saturation current (multiple of theoretical minimum) & $\begin{array}{l}10 \\
+0.7 \% \\
\end{array}$ & 100 & $\begin{array}{l}1,000 \\
-1.0 \%\end{array}$ \\
\hline Shunt resistance & $\begin{array}{l}100,000 \Omega / \mathrm{cm}^{2} \\
+0 \%\end{array}$ & $10,000 \Omega / \mathrm{cm}^{2}$ & $\begin{array}{l}1,000 \Omega / \mathrm{cm}^{2} \\
-1.4 \%\end{array}$ \\
\hline Series resistance & $\begin{array}{l}0.2 \Omega \mathrm{cm}^{2} \\
+0.2 \%\end{array}$ & $1 \Omega \mathrm{cm}^{2}$ & $\begin{array}{l}5 \Omega \mathrm{cm}^{2} \\
-1.0 \% \\
\end{array}$ \\
\hline OER onset overpotential $\left(1 \mathrm{~mA} / \mathrm{cm}^{2}\right)$ & $\begin{array}{l}280 \mathrm{mV} \\
+0.2 \%\end{array}$ & $320 \mathrm{mV}$ & $\begin{array}{l}360 \mathrm{mV} \\
-0.3 \%\end{array}$ \\
\hline OER Tafel slope & $\begin{array}{l}30 \mathrm{mV} / \text { decade } \\
+0.1 \%\end{array}$ & $40 \mathrm{mV} /$ decade & $\begin{array}{l}60 \mathrm{mV} / \text { decade } \\
-0.2 \%\end{array}$ \\
\hline Ionic path length & $\begin{array}{l}0.25 \mathrm{~cm} \\
+0.6 \% \\
\end{array}$ & $0.5 \mathrm{~cm}$ & $\begin{array}{l}1 \mathrm{~cm} \\
-1.6 \% \\
\end{array}$ \\
\hline
\end{tabular}

Table S1 Sensitivity of the STF efficiency for changes in modelling parameters for $\mathrm{CO}_{2}$ to

CO reduction. The STF efficiency with the standard parameters is $\mathbf{2 0 . 0} \%$ for this reaction. The change in STF efficiency (in absolute \%) is shown when any one of the standard parameters is changed to the values stated.

The change in STF efficiency for with a change of the optical light loss - or the faradaic efficiency is trivial and therefore not included in table S1. As the data in Table S1 shows, improving the tandem solar absorber in terms of shunt resistance or series resistance has very limited benefit, but on the other hand, there is a loss as these parameters worsen. Within a reasonable range, the OER catalysis parameters only affect the STF efficiency moderately, and the same is true for the thickness of the water layer (photons below $1.3 \mathrm{eV}$ aren't absorbed anyway). The conclusion is that effort should be focused on making a good absorber stack and on minimizing the equivalent ionic path length. 